\title{
Efficacy of radiation synovectomy (radiosynovectomy or radiosynoviorthesis) with yttrium-90 in exudative inflammation of synovial membrane of knee joints in patients with rheumatic diseases - preliminary report
}

\author{
Joanna Zalewska ${ }^{1}$, Małgorzata Węgierska ${ }^{1}$, Tacjana Barczyńska' ${ }^{1}$, Marzena Waszczak², \\ Paweł Żuchowski ${ }^{3}$, Stawomir Jeka ${ }^{1}$ \\ ${ }^{1}$ Department of Rheumatology and Connective Tissue Diseases, J. Biziel University Hospital No. 2, Bydgoszcz, Ludwik Rydygier, \\ Collegium Medicum in Bydgoszcz, UMK in Torun, Poland \\ ${ }^{2}$ Centre for Clinical Trials, Warsaw, Poland \\ ${ }^{3}$ Independent Section of Scientific Research Coordination, J. Biziel University Hospital No. 2, Bydgoszcz, Poland
}

\begin{abstract}
Objectives: Hypertrophic and exudative synovitis of the knee is one of the earliest symptoms in rheumatic diseases. In the case of pharmacotherapy failure, other methods which directly remove the inflamed synovial membrane are used - synovectomies. Radiosynovectomy (RSV) is the radiopharmaceutical application of colloidal solution to joint cavities. In this study, the authors assessed the efficacy of knee radiosynovectomy with yttrium-90 (Y-90) in several groups of patients divided into certain rheumatic diseases.

Material and methods: The study group consisted of 70 patients aged from 29 to 65 years with hypertrophic and exudative synovitis of the knee in rheumatic diseases such as rheumatoid arthritis, osteoarthrosis and spondyloarthropathies. Radiopharmaceutical colloid of Y-90, with a radiation dose of 185-222 MBq in a volume of 2-3 ml, was administered to joint. Then the knee joint was immobilized for $72 \mathrm{~h}$. During visits V1, V2, V3 and V4, erythrocyte sedimentation rate (ESR) and $C$-reactive protein (CRP) were measured and ultrasound of the knee was performed. Disease activity was evaluated by the WOMAC scale, HAQ and 100-mm visual analog scale (VAS).

Results: The most significant difference of synovial hypertrophy, before and after the procedure, was obtained in patients with rheumatoid arthritis. Variability of effusion before and after the procedure in all groups was comparable and statistically significant. The greatest improvement in variability of inflammatory parameters, before and 4 weeks after radiosynovectomy, was observed in patients with rheumatoid arthritis.

Conclusions: In the therapeutic algorithm radiosynovectomy should be located between conservative treatment and operative procedures. Radiosynovectomy does not require hospitalization or prolonged rehabilitation. Radiosynoviorthesis affects the patient's general condition, which is associated with eliminating pain and restoring joint function.
\end{abstract}

Key words: knee, hypertrophic-exudative synovitis, radiosynovectomy.

Address for correspondence:

Joanna Zalewska, Department of Rheumatology and Connective Tissue Diseases, J. Biziel University Hospital No. 2,

Ujejskiego 75, 85-168 Bydgoszcz, Poland, e-mail: asia_zetka@wp.pl

Submitted: 22.10.2015; Accepted: 22.02.2016 


\section{Introduction}

Hypertrophic and exudative synovitis of the knee is one of the earliest symptoms in rheumatic diseases. In the case of pharmacotherapy failure, other methods which directly remove the inflamed synovial membrane are used - "synovectomies" (from Greek: synovium - synovial membrane, ectomia - ectomy or cutting). There are chemical, radioisotope and surgical synovectomies. Surgical synovectomy is the surgical removal of inflammatory synovium during arthroscopy or open surgery synovectomy. In chemical and radioisotope synovectomy, for the knee joint cavity an appropriate substance is given, such as Aethoxysklerol in chemical synovectomy or radionuclide colloidal solution of radiopharmaceutical yttrium-90 (Y-90) in radiosynovectomy (RSV) [1, 2].

For the first time, radionuclide synovectomy (radiosynovectomy) was performed in 1952 by the Austrian physician Karl Fehlinger. He applied a colloidal solution of gold radioisotope to the knee joints in patients with rheumatoid arthritis (RA). In 1968 Delbarre introduced the term radiosynoviorthesis (RS), which comes from the Greek word ortesis and means the reconstruction of the synovial membrane by radionuclides [3].

In Poland, for the first time in 1969, Irena Fiedorowicz-Fabrycy conducted radiosynoviorthesis using a radioisotope of radioactive phosphorus (P-32) in 136 knee joints: a group of 112 patients with RA, ankylosing spondylitis, psoriatic arthritis and juvenile idiopathic arthritis [4].

Radiosynovectomy is the radiopharmaceutical application of colloidal solution to the cavity joint. Radiopharmaceutical is composed of radioisotope and a ligand [5]. The most commonly used radioisotopes are Y-90, rhenium-186, erbium-169, and phosphorus-32. They are associated with ligands such as citrate and silicate (sulfide, ferric hydroxide). Radioisotopes emit $\beta$ radiation. $\beta$ particles are phagocytosed by macrophages, and the processes of sclerosis and fibrosis in the synovial membrane are present. In radiosynovectomy ionizing radiation is used, and the procedure requires specific conditions which include isotope laboratory. Extremely important is the size of the radioisotope particle, the range of radiation and half-life period of the radioisotope, as these factors affect the choice of type of joint to which radioisotope is administered [6].

The aim of the study was to assess the clinical efficacy of Y-90 radiosynovectomy in hypertrophic and exudative knee synovitis in patients with rheumatic diseases: rheumatoid arthritis, osteoarthrosis and peripheral spondyloarthropathies (psoriatic arthritis and ankylosing spondylitis).

\section{Material and methods \\ Study group}

The study group comprised 70 patients aged from 29 to 65 years (51 women and 19 men) with hypertrophic and exudative synovitis of the knee in confirmed inflammatory and non-inflammatory rheumatic diseases such as RA (34 patients), peripheral spondyloarthropathies (SpA) (17 patients -7 patients with psoriatic arthritis and 10 patients with ankylosing spondylitis) and osteoarthrosis (OA) (19 patients). A radiopharmaceutical colloid of $Y-90$, with a radiation dose of 185-222 MBq in a volume of 2-3 ml, was administered to the joint, after the puncture with fluid removal. Then the knee joint was immobilized for $72 \mathrm{~h}$.

The study was approved by an ethics committee and patient informed consent was obtained. The patients were observed in the Rheumatology Outpatient Clinic of Jan Biziel University Hospital in Bydgoszcz in 2009-2012. The most important inclusion criteria were: hypertrophic and exudative knee synovitis (diagnosed in ultrasound examination of knee) with duration of symptoms at least 6 months, despite pharmacotherapy with DMARDs and NSAIDs with duration of pharmacotherapy at least 6 months (there was no change in pharmacotherapy during the study), and therapeutic failure after 2 knee injections of glucocorticosteroids.

\section{Clinical study visits}

During visit 1 (V1), for each patient the concentrations of acute phase indicators (such as ESR and CRP) were determined, and ultrasound of the knee was performed, with measurement of the thickness of the synovial membrane, quantity of synovial fluid in the suprapatellar recess and synovial vascular flow in power color Doppler (PD). Disease activity was also evaluated by the HAQ (Health Assessment Questionnaire) and WOMAC knee (Western Ontario and McMaster Universities Osteoarthritis Index) scale. Disease activity was also assessed by the patient and physician using a 100-mm visual analog scale (VAS). Assessment of the patient's pain intensity using a numerical 10-grade scale for 7 consecutive days prior to the procedure was performed (the patient's diary) (Fig. 1).

During subsequent visits V2 (1 month after RSV), V3 (3 months after RSV) and V4 (6 months after RSV) measurement of concentrations of acute phase indicators (ESR and CRP), USG of the knee, WOMAC and HAQ scales, the assessment of disease activity by VAS evaluation of disease activity by patient and physician, and intensity of pain for 7 consecutive days after removing the immobilizer were done. 


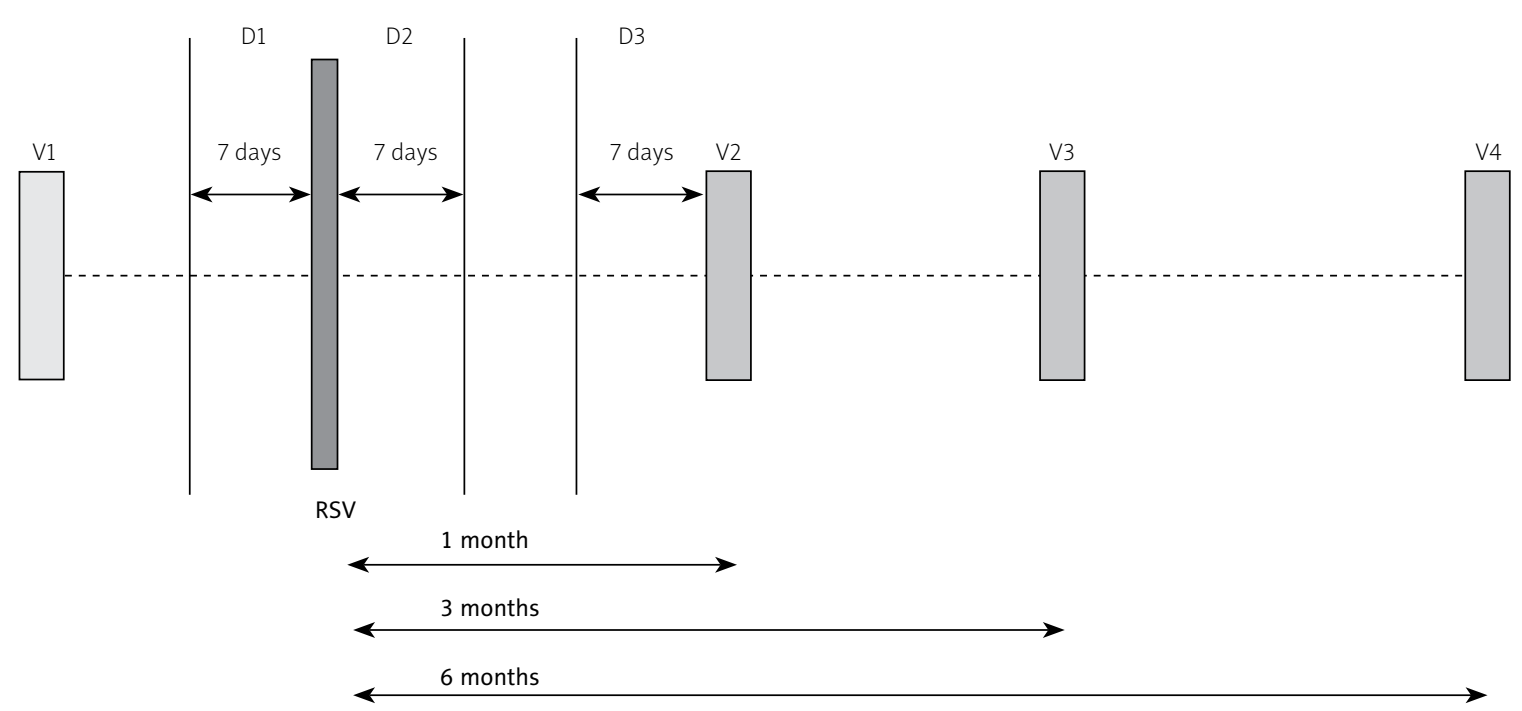

Scheme:

V1 - screening visit

$\mathrm{V} 2$ - control visit -1 month after procedure

V3 - control visit -3 months after procedure

V4 - control visit -6 months after procedure

RSV - radioisotope administration

D1 - diary - pain intensity -7 consecutive days prior to procedure

D2 - diary - pain intensity - 7 consecutive days after procedure

D3 - diary - pain intensity - 7 consecutive days prior to control visit

Fig. 1. Visit plan.

\section{Statistical analysis}

Statistical analysis was performed using the Statistica software (StatSoft, Oklahoma, USA). Where necessary, the arithmetic mean $(M)$ and standard deviation (SD) were used to describe intervariability within quantitated parameters. Statistical significance between data groups was determined by analysis of variance (ANOVA) and Student's $t$ test. The Wilcoxon nonparametric test was used to assess statistical significance in data groups which were shown to deviate significantly from a normal Gaussian distribution. Quantitative parameters were analyzed using the $\chi^{2}$ test. In all cases, statistical significance was designated with a $p$-value $<0.05$.

\section{Results}

The reduction in synovial hypertrophy before RSV and 1 month after RSV (comparing data between V1 and V2) was statistically significant in all 3 groups of patients. The most significant difference of synovial hypertrophy, seen in ultrasonography, before and after the procedure, was obtained in patients with rheumatoid arthritis. Variability of effusion before and after the procedure in ultrasound imaging in all groups was compa- rable and statistically significant. The greatest improvement in variability of inflammatory parameters before and 1 month after radiosynovectomy was observed in patients with rheumatoid arthritis. The results in the effusion measurements, the average reduction in effusion before and after the RSV, were statistically significant in each group of patient. The results between the groups were statistically comparable.

The results of these measurements are shown in Table I.

In the WOMAC scale statistically significant variation for all parameters, such as pain intensity (Table II), stiffness (Table III) and difficulty in performing daily activities (Table IV), was obtained only in patients with RA.

The greatest variability in difficulty in climbing stairs was observed in patients with osteoarthrosis, and in descending the stairs in patients with RA. In a standing position, statistical variation was significant and comparable in all groups. The WOMAC scale of the daily activities of patients did not achieve statistically significant variability in either group of patients.

We observed that in patients with OA the reduction of pain intensity was statistically significant in four out of five categories (Table II). However, patients with spondyloarthropathies presented statistically signifficant improvement in pain intensity only in one of the five categories (Table II). As shown in Table III, we 
Table I. Comparison of parameters before and 1 month after radiosynovectomy in all 3 groups of patients

\begin{tabular}{|c|c|c|c|c|c|c|c|c|c|}
\hline & \multicolumn{3}{|c|}{$\mathrm{RA}^{\mathrm{a}}(n=34)$} & \multicolumn{3}{|c|}{$\operatorname{SpA}^{\mathrm{b}}(n=17)$} & \multicolumn{3}{|c|}{$\mathrm{OA}^{c}(n=19)$} \\
\hline & pre-RSV ${ }^{d}$ & post-RSVe & $p<0.05 ?^{f}$ & pre-RSVd & post-RSVe & $p<0.05 ?^{f}$ & pre-RSV ${ }^{d}$ & post-RSVe & $p<0.05 ?^{f}$ \\
\hline $\begin{array}{l}\text { Synovial } \\
\text { hypertrophy } \\
(\mathrm{mm})\end{array}$ & $7.62 \pm 2.57$ & $4.71 \pm 1.85$ & yes & $7.53 \pm 2.32$ & $5.12 \pm 1.83$ & yes & $7.11 \pm 2.75$ & $4.26 \pm 1.33$ & yes \\
\hline $\begin{array}{l}\text { Effusion } \\
(\mathrm{mm})\end{array}$ & $8.91 \pm 3.65$ & $5.53 \pm 2.95$ & yes & $8.82 \pm 3.40$ & $5.18 \pm 2.60$ & yes & $7.63 \pm 2.39$ & $4.26 \pm 2.10$ & yes \\
\hline $\begin{array}{l}\text { ESR } \\
(\mathrm{mm} / \mathrm{h})\end{array}$ & $22.24 \pm 20.01$ & $11.88 \pm 10.23$ & yes & $17.12 \pm 16.61$ & $11.71 \pm 11.27$ & yes & $18.05 \pm 16.12$ & $9.32 \pm 8.89$ & yes \\
\hline $\begin{array}{l}\text { CRP } \\
(\mathrm{mg} / \mathrm{l})\end{array}$ & $14.83 \pm 19.88$ & $5.32 \pm 5.52$ & yes & $14.74 \pm 12.37$ & $5.09 \pm 4.19$ & yes & $12.25 \pm 7.67$ & $4.48 \pm 6.24$ & yes \\
\hline
\end{tabular}

${ }^{a}$ Designates rheumatoid arthritis; ${ }^{b}$ Designates spondyloarthropathies; ${ }^{c}$ Designates osteoarthrosis; ${ }^{d}$ Denotes prior to radiosynovectomy; eDenotes 1 month after radiosynovectomy; $f_{a} p$-value $<0.05$ indicates statistical significance

Table II. WOMAC index for pain intensity before and 1 month after radiosynovectomy in all 3 groups of patients

\begin{tabular}{|c|c|c|c|c|c|c|c|c|c|}
\hline & \multicolumn{3}{|c|}{$\mathrm{RA}^{\mathrm{a}}(n=34)$} & \multicolumn{3}{|c|}{$\operatorname{SpA}^{\mathrm{b}}(n=17)$} & \multicolumn{3}{|c|}{$\mathrm{OA}^{\mathrm{c}}(n=19)$} \\
\hline & pre-RSV ${ }^{d}$ & post-RSV & $p<0.05 ?^{f}$ & pre-RSV ${ }^{d}$ & post-RSV & $p<0.05 ?^{f}$ & pre-RSV ${ }^{d}$ & post-RSV & $p<0.05 ?^{f}$ \\
\hline $\begin{array}{l}\text { Walking on } \\
\text { flat surface }\end{array}$ & $39.35 \pm 22.69$ & $29.74 \pm 17.09$ & yes & $46.82 \pm 16.99$ & $41.24 \pm 13.37$ & no & $37.37 \pm 20.07$ & $29.32 \pm 17.05$ & yes \\
\hline $\begin{array}{l}\text { Walking up } \\
\text { stairs }\end{array}$ & $56.94 \pm 26.80$ & $45.41 \pm 22.91$ & yes & $59.29 \pm 23.62$ & $55.29 \pm 19.09$ & no & $59.79 \pm 24.53$ & $45.11 \pm 22.20$ & yes \\
\hline $\begin{array}{l}\text { During night, } \\
\text { in bed }\end{array}$ & $35.35 \pm 27.00$ & $27.12 \pm 20.54$ & yes & $34.11 \pm 25.67$ & $30.47 \pm 23.91$ & no & $30.21 \pm 24.91$ & $28.11 \pm 18.96$ & no \\
\hline $\begin{array}{l}\text { In sitting or } \\
\text { lying position }\end{array}$ & $29.88 \pm 21.44$ & $22.71 \pm 17.05$ & yes & $32.18 \pm 20.92$ & $29.65 \pm 17.87$ & no & $34.89 \pm 27.08$ & $27.42 \pm 17.87$ & yes \\
\hline $\begin{array}{l}\text { In standing } \\
\text { position }\end{array}$ & $44.53 \pm 21.93$ & $36.41 \pm 19.47$ & yes & $46.29 \pm 21.20$ & $37.76 \pm 22.62$ & yes & $48.42 \pm 23.08$ & $28.37 \pm 17.84$ & yes \\
\hline
\end{tabular}

${ }^{a}$ Designates rheumatoid arthritis; ${ }^{b}$ Designates spondyloarthropathies; ${ }^{c}$ Designates osteoarthrosis; ${ }^{d}$ Denotes prior to radiosynovectomy; eDenotes 1 month after radiosynovectomy; $f_{a} p$-value $<0.05$ indicates statistical significance

observed the statistically significant reduction in knee stiffness, in both categories, only in patients with rheumatoid arthritis.

In patients with RA a gradual reduction of pain intensity in all weekly assessments of pain intensity (VAS pain) was observed, whereas in patients with osteoarthrosis and spondyloarthropathies only I and III of the reference week was noticed. The results are shown in Table $\mathrm{V}$.
Variability in the assessment of the health questionnaire (HAQ) was not statistically significant, but the greatest improvement was observed in patients with rheumatoid arthritis. Based on the results of tests and measurements, radiosynovectomy was effective in all patient groups, with statistically significant values ( $p<0.005)$, but the greatest statistical variability was observed in patients with RA, suggesting the best therapeutic effect for these patients.

Table III. WOMAC index for knee stiffness before and 1 month after radiosynovectomy in all 3 groups of patients

\begin{tabular}{|lccccccccc|}
\hline & \multicolumn{3}{c}{ RA $^{\mathrm{a}}(n=34)$} & \multicolumn{3}{c}{ SpA $^{\mathrm{b}}(n=17)$} & \multicolumn{3}{c|}{ OA $^{\mathrm{c}}(n=19)$} \\
\cline { 2 - 9 } & pre-RSV $^{\mathrm{d}}$ & post-RSV & $p<0.05 ?^{\mathrm{f}}$ & pre-RSV $^{\mathrm{d}}$ & post-RSV & $p<0.05 ?^{\mathrm{f}}$ & pre-RSV $^{\mathrm{d}}$ & post-RSV $^{\mathrm{p}}$ & $p<0.05 ?^{f}$ \\
\hline $\begin{array}{l}\text { Following } \\
\text { morning } \\
\text { awakening }\end{array}$ & $46.09 \pm 27.54$ & $35.82 \pm 22.52$ & yes & $44.53 \pm 27.99$ & $36.65 \pm 22.80$ & no & $37.89 \pm 23.44$ & $32.95 \pm 17.55$ & no \\
\hline $\begin{array}{l}\text { During the } \\
\text { day }\end{array}$ & $43.94 \pm 22.82$ & $34.56 \pm 21.01$ & yes & $48.00 \pm 25.25$ & $38.47 \pm 20.32$ & yes & $41.47 \pm 17.50$ & $34.79 \pm 17.01$ & yes \\
\hline
\end{tabular}

${ }^{a}$ Designates rheumatoid arthritis; ${ }^{b}$ Designates spondyloarthropathies; ${ }^{\circ}$ Designates osteoarthrosis; ${ }^{d}$ Denotes prior to radiosynovectomy;

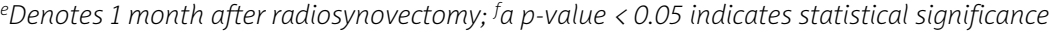


Table IV. WOMAC index for difficulty in performing daily activities before and 1 month after radiosynovectomy in all 3 groups of patients

\begin{tabular}{|c|c|c|c|c|c|c|c|c|c|}
\hline & \multicolumn{3}{|c|}{$\mathrm{RA}^{\mathrm{a}}(n=34)$} & \multicolumn{3}{|c|}{$\operatorname{SpA}^{\mathrm{b}}(n=17)$} & \multicolumn{3}{|c|}{$\mathrm{OA}^{c}(n=19)$} \\
\hline & pre-RSV ${ }^{d}$ & post-RSVe & $p<0.05 ?^{f}$ & pre-RSV ${ }^{d}$ & post-RSVe & $p<0.05 ?^{f}$ & pre-RSV ${ }^{d}$ & post-RSVe & $p<0.05 ?^{f}$ \\
\hline $\begin{array}{l}\text { Going down } \\
\text { stairs }\end{array}$ & $59.26 \pm 25.87$ & $47.76 \pm 22.71$ & yes & $61.41 \pm 21.46$ & $55.59 \pm 16.24$ & no & $50.89 \pm 25.28$ & $40.26 \pm 25.60$ & yes \\
\hline $\begin{array}{l}\text { Climbing } \\
\text { stairs }\end{array}$ & $57.00 \pm 27.79$ & $46.21 \pm 23.16$ & yes & $57.29 \pm 26.25$ & $46.76 \pm 18.95$ & yes & $47.16 \pm 25.10$ & $38.63 \pm 25.76$ & yes \\
\hline $\begin{array}{l}\text { Rising from } \\
\text { seated } \\
\text { position }\end{array}$ & $48.68 \pm 25.42$ & $36.68 \pm 22.02$ & yes & $48.94 \pm 25.15$ & $38.65 \pm 19.41$ & no & $39.63 \pm 23.30$ & $35.00 \pm 21.38$ & no \\
\hline Standing & $50.82 \pm 26.22$ & $37.68 \pm 21.35$ & yes & $48.00 \pm 28.24$ & $436.00 \pm 20.06$ & yes & $40.47 \pm 22.60$ & $32.84 \pm 19.88$ & yes \\
\hline $\begin{array}{l}\text { Bending to } \\
\text { the floor }\end{array}$ & $49.74 \pm 26.77$ & $44.29 \pm 23.85$ & yes & $49.94 \pm 30.32$ & $42.18 \pm 24.24$ & no & $41.74 \pm 26.06$ & $36.89 \pm 25.09$ & no \\
\hline
\end{tabular}

${ }^{a}$ Designates rhe umatoid arthritis; ${ }^{b}$ Designates spondyloarthropathies; ' Designates osteoarthrosis; ${ }^{d}$ Denotes prior to radiosynovectomy;

${ }^{e}$ Denotes 1 month after radiosynovectomy; ${ }^{f}$ a $p$-value $<0.05$ indicates statistical significance

Table V. Assessment of pain intensity according to the 7-day visual analog scale in all 3 groups of patients. Results were analyzed 7 days before radiosynovectomy (RSV), 7 days after RSV and 7 days before visit 2 (1 month after RSV)

\begin{tabular}{|c|c|c|c|c|c|c|}
\hline & \multirow{2}{*}{$\begin{array}{l}\text { Prior to RSV } \\
\text { procedure }(I)^{\mathrm{a}}\end{array}$} & \multirow{2}{*}{$\begin{array}{l}\text { Following RSV } \\
\text { procedure (II) }\end{array}$} & \multirow{2}{*}{$\begin{array}{l}\text { Four weeks following } \\
\text { RSV procedure (III) }\end{array}$} & \multicolumn{3}{|c|}{$p<0.05 ?^{b}$} \\
\hline & & & & | vs. II & II vs. III & | vs. III \\
\hline $\mathrm{RA}^{\mathrm{c}}$ & $4.92 \pm 1.93$ & $3.86 \pm 2.05$ & $2.86 \pm 2.10$ & yes & yes & yes \\
\hline $\mathrm{SpA}^{\mathrm{d}}$ & $4.57 \pm 1.93$ & $4.72 \pm 1.51$ & $3.38 \pm 1.38$ & no & yes & yes \\
\hline$O A^{e}$ & $4.52 \pm 2.32$ & $3.75 \pm 2.43$ & $2.68 \pm 1.07$ & no & no & yes \\
\hline
\end{tabular}

${ }^{a} R S V$ denotes radiosynovectomy; ${ }^{b} p$-value $<0.05$ indicates statistical significance; ${ }^{c}$ Designates rheumatoid arthritis. ${ }^{d}$ Designates spondyloarthropathies; ${ }^{e}$ Designates osteoarthrosis

\section{Discussion}

In this publication, the authors decided to assess the efficacy of knee radiosynovectomy with yttrium-90 in several groups of patients divided into certain rheumatic diseases. We evaluated the efficacy of the procedure, using laboratory tests for measurement of inflammatory parameters (among others ESR and CRP) and ultrasound for assessment of inflammatory fluid quantity and inflammatory synovial hypertrophy. We evaluated the VAS scale of disease activity by a physician and patient and we also assessed weekly evaluation of pain intensity scored in the 10-point numerical scale, general assessment of patient's health status by HAQ questionnaire and evaluation of pain and stiffness of the knee while performing certain activities by WOMAC.

In our results we found beneficial effects of RSV treatment in the quantity of inflammatory fluid of the knee. However, some authors disagree with this statement. Miszczyk et al. conducted RSV of the knee with Y-90 in a group of patients with rheumatoid arthritis (5 patients), pigmented villonodular synovitis (3), psoriatic arthritis (PSA) (3) and ulcerative colitis (2). In a study published in 2007, they did not make a clear assessment of the effectiveness of RSV. The authors mentioned the very small size of the patient group. However, they observed a decline in the number of punctures of the knee during subsequent control visits. However, no satisfactory results were obtained in the assessment of joint motion and circumference at subsequent visits after 2 , 4, 12 weeks, and 6 and 12 months. In a paper published two years later in a group of 81 patients, the authors found that RSV did not have a significant impact on joint mobility and volume of inflammatory fluid, evaluated at the last visit, compared to the volume of fluid evaluated at the initial visit. The authors also did not obtain a significant improvement in evaluation of the circumference of the knee. However, they obtained a decrease of pain in $43.5 \%$ two weeks after treatment and a $20 \%$ decrease at the last visit. They also noted an increase of percentage in the group with complete resolution of pain from $8.5 \% 2$ weeks after treatment to $60 \%$ one year after treatment and a decrease of inflammatory fluid evacuated from the joint during subsequent punctures [7, 8].

Inefficiency of RSV was also reported by Jahangier et al., who conducted a study comparing the effectiveness of intraarticular injection of Y-90, including preparations of steroids, to glucocorticoid injections. 
The authors did not obtain a statistically significant difference in the effectiveness of the two methods and found that RSV should not be the method of first choice in treating hypertrophic synovitis of the knee [9]. O'Duffy et al. also shared this point of view. They conducted a double-blind study which showed no advantage of knee RSV using samarium-153 in comparison to glucocorticoid injections [10]. The above-mentioned study conducted by Jahangier et al. has been undermined by Kampen et al. [6], who claimed that it cannot refute the effectiveness of RS. They pointed to the lack of homogeneity of the study group in duration of synovitis joints and failure to fulfill one of the most important criteria - the lack of effectiveness of intraarticular injection of glucocorticoid twice.

However, Roch-Bras et al. [11] described the improvement in pain, mobility and quantity of joint effusions in $70.7 \%$ after RSV. Fischer and Modder [12] assessed the proportion of patients with 60-80\%, and Jahangier et al. [9] and Kampen et al. [6], respectively, 34\% and 75\%.

Positive results of early follow-up at 6 months after radioisotope administration of $\mathrm{P}-32$ were also obtained by Fiedorowicz-Fabrycy. She observed an excellent outcome - complete resolution of effusion and pain - in $71.7 \%$ of treated knee joints. The best results were seen in patients with PsA, ankylosing spondylitis and in patients with RA of second stage in the Steinbrocker classification [4].

Also Chrapko et al. [13] in their results confirmed the beneficial effect of RSV using yttrium-90. At 24 weeks after RSV was performed, effusion was noted in only 9.4\% of patients with RA. The authors also observed a significant decrease in rates of acute phase protein (CRP) at 4 and 24 weeks after the procedure was done. In our study group we observed the best results in patients with RA. Positive results for reducing levels of acute phase indicators ESR and CRP were obtained by Boerbooms et al., who studied two groups of patients with RA - with minimal radiological changes and with significant changes in the $\mathrm{X}$-ray image. They concluded that better results for the reduction of ESR were obtained in patients in early stages of the disease. The authors also stated that better results were achieved in patients in the early stages of the disease, one year after RSV. The efficacy in this group was 58\%, compared with $25 \%$ in a group of patients during advanced disease [14].

The results we obtained in the study group patients correlate with the meta-analysis conducted by Kresnik et al. [14], who found that in a group of 1417 knee joints treated with Y-90, the best efficacy was found in patients with rheumatoid arthritis and early stage of the Steinbrocker classification.

\section{Conclusions}

In the therapeutic algorithm the radiosynovectomy procedure should be located between conservative treatment and operative procedures. The greatest advantage of this method is not excluding the eventuality of surgery at a later time. Radiosynovectomy does not require hospitalization and prolonged rehabilitation. The duration of treatment is short, and it can be repeated many times. It should be stressed that radiosynovectomy can be performed in elderly patients in whom the operative risk is very high.

The method is especially useful in the group of patients with early RA, while the late stage of the disease, with significant hypertrophy of the synovial membrane, is an indication for surgical synovectomy [2]. By including questionnaires, e.g. quality of life of the patient, we intended to emphasize that RSV may affect the patient's general condition, which is associated with eliminating pain and restoring joint function. The parameters of laboratory tests performed before and after the procedure indicate that the above-mentioned statement is essential. At this moment, we have presented our preliminary reports of the first part of obtained results, and the others are in preparation.

The authors declare no conflict of interest.

\section{References}

1. Zwolak R, Majdan M, Zaorska-Rajca J, et al. Porównanie skuteczności oraz ocena wpływu synowiortezy chemicznej i radioizotopowej na nasilenie procesu zapalnego w terapii uporczywych wysięków w stawach kolanowych. Reumatologia 2005; 43: 327-330.

2. Hagner W, Jeka S, et al. Ręka reumatoidalna - leczenie zachowawcze. In: Ręka reumatoidalna. UMK CM, Bydgoszcz 2006; 106-110.

3. Delbarre F, Cayla J, Menkes C, et al. La synoviorthese par les radio-isotypes. Pres Med 1968; 76: 1045-1050.

4. Fiedorowicz-Fabrycy I. Wyniki leczenia przewlekłych wysiękowych zapaleń stawów kolanowych za pomocą synowiortezy izotopowej P-32 w świetle badań własnych. Ann Acad Med Stetin 1984; 30: 321-357.

5. Królicki L. Medycyna nuklearna. Fundacja im. Ludwika Rydygiera, Warszawa 1996; 30-33.

6. Kampen WU, Brenner W, Czech N, et al. Intraarticular application of unsealed beta-emitting radionuclides in the treatment course of inflammatory joint diseases. Curr Med Chem - AntiInflammatory Anti-Allergy Agents 2002; 1: 77-87.

7. Miszczyk L, Woźniak G, Jochymek B, et al. Ocena skuteczności radiosynowektomii stawu kolanowego przy użyciu 90Y. Przegl Lek 2007; 64: 450-453.

8. Miszczyk L, Jochymek B, Spindel J, et al. Radiosynowektomia stawu kolanowego - doświadczenia własne. Chir Narz Ruchu Ortop Pol 2009; 74: 151-157. 
9. Jahangier ZN, Moolenburgh JD, Jacobs JW, et al. The effect of radiation synovectomy in patients with persistent arthritis: a prospective study. Clin Exp Rheumatol 2001; 19: 417-424.

10. O’Duffy EK, Clunie GP, Lui D, et al. Double blind glucocorticoid controlled trial of samarium-153 particulate hydroxyapatite radiation synovectomy for chronic knee synovitis. Ann Rheum Dis 1999; 58: 554-558.

11. Roch-Bras F, Daurès JP, Legouffe MC, et al. Treatment of chronic knee synovitis with arthroscopic synovectomy: longterm results. J Rheumatol 2002; 29: 1171-1175.

12. Fischer M, Modder G. Radionuclide therapy of inflammatory joint diseases. Nucl Med Commun 2002; 23: 829-831.

13. Chrapko B, Zwolak R, Nocuń A, et al. Radiation synovectomy with $90 Y$ colloid in the therapy of recurrent knee joint effusions in patients with inflammatory joint diseases. Rheumatol Int 2007; 27: 729-734.

14. Kresnik E, Mikosch P, Gallowitsch HJ, et al. Clinical outcome of radiosynoviorthesis: a meta-analysis including 2190 treated joints. Nucl Med Commun 2002; 23: 683-688. 